\title{
REPUTAÇÕES À BRASILEIRA: O CASO DE GUERREIRO RAMOS ${ }^{1}$
}

Um estudante de graduação em Ciências Sociais em qualquer universidade brasileira dificilmente deixará seu curso sem ter lido algo de Karl Marx, Max Weber e Émile Durkheim. Em geral, estes autores são estudados nas primeiras disciplinas de formação, nas quais se aprende que tal trindade forma os clássicos da disciplina. Entretanto, pouquíssimos formandos refletirão, em algum momento, sobre as razões que presidiram a construção de tal cânone. Em boa parte das vezes, a nossa compreensão ordinária da história da sociologia ${ }^{2}$ limita-se a registrar a narrativa consagradora de tal literatura, pouco se perguntando sobre os motivos que possam explicar o jogo de seleções/rejeições que governa a escolha dos clássicos.

Dito de outra maneira, nós pouco nos inquirimos sobre a sociologia das reputações intelectuais, e esta lacuna afeta especialmente a sociologia brasileira. Este artigo busca discutir este tema a partir de um estudo de caso centrado no sociólogo baiano Alberto Guerreiro Ramos (1915-1982). Um dos mais conhecidos cientistas sociais do país nos anos de 1950 e 1960, Guerreiro conheceu período de ostracismo intelectual a partir de 1964, partilhando o descrédito de que foi alvo todo tipo de produção intelectual associada ao chamado regime populista. Este quadro de ostracismo começou a mudar a partir dos anos de 1990, quando numerosas teses passaram a ser escritas sobre ele, visando uma reconversão de sua imagem intelectual no mercado acadêmico, até então em franco declínio.

Entretanto, esta estratégia não logrou ainda desfazer uma série de mal-entendidos sobre a obra desse autor e seu lugar na história da sociologia. Ainda permanece a reputação de Guerreiro como uma espécie de outsider, figura gauche que surge como um desvio de rota no caminho da sociologia acadêmica e especializada. O texto, portanto, não busca apenas discutir a produção histórica do lugar de Guerreiro na nossa memória coletiva, mas também visa a utilizar esta discussão criticamente para apresentar um novo ponto de vista sobre a sua inscrição no campo mais amplo da sociologia. Esta visão baseia-se na defesa da atualidade da produção de Guerreiro em relação aos 
debates sociológicos globais de seu tempo. Trata-se, então, de desprovincializar este intelectual, relativizando, portanto, o nacionalismo e o isebianismo como chaves de leitura para a sua obra.

$\mathrm{O}$ artigo tem três seções. Na primeira, discuto dois eixos teóricos que produziram importantes contribuições analíticas para o problema levantado neste texto: a teoria da recepção, tal como apresentada na obra de Hans Jauss, e os estudos sociológicos sobre a construção de reputações intelectuais. Em seguida, analiso os diferentes momentos históricos cruciais para a construção da reputação de Guerreiro Ramos na história de nossas ciências sociais, destacando a passagem de uma abordagem mais crítica, produzida na segunda metade da década de 1970, para análises mais matizadas que buscavam resgatar o prestígio do autor. Na terceira seção do artigo, apresento alguns dados que permitem completar o movimento apontado acima, evidenciando o lugar mais preciso ocupado por Guerreiro no quadro da ciência sociológica propriamente dita, para além da narrativa que o situa no âmbito do ISEB ou do pensamento nacionalista. Para tanto, emprego dois recursos metodológicos básicos: a leitura e o rastreamento de citações em textos tidos como não-exemplares do autor, em especial aqueles referentes aos anos de 1940 e à sua fase americana, pós-exílio; e a apresentação de outros discursos sociológicos não-brasileiros no mesmo período, que evidenciam a conexão entre a produção do autor e correntes mais amplas da sociologia global.

\section{RECEPÇÃO E REPUTAÇÃo}

Pode-se dizer que há duas grandes tradições interpretativas no que se refere ao estudo da forma como intelectuais e ideias são legitimados ou deslegitimados historicamente. Um primeiro campo organiza-se em torno dos estudos literários de recepção, em especial por intermédio da obra de Hans Jauss (Jauss, 1970; 1982), na qual são investigados como os sentidos do texto clássico podem ser alterados ou reinterpretados em função de novas leituras feitas por comunidades interpretativas situadas em tempos históricos diversos. O segundo campo, que encontra seu fundamento nos trabalhos de Pierre Bourdieu e nas releituras da obra bourdiana à luz da sociologia da ciência, encontra seus melhores desdobramentos em alguns trabalhos de "sociologia da sociologia" (Camic, 1992; Lamont, 1987; McLaughlin, 1998). Sugiro que as duas linhagens apresentam ferramentas analíticas relevantes para o caso analisado neste artigo.

A teoria da recepção, tal como trabalhada por Hans Jauss, visava deslocar o culto atemporal dos clássicos e evidenciar a dimensão hermenêutica presente na atividade de leitura de textos do passado. Jauss argumentou que o significado de um texto não se encontraria encerrado de forma imutável no próprio objeto literário em si, pois este só revelaria todo o seu campo de sig- 
nificação quando lido ao longo da História. Faz-se necessário, portanto, investigar como diferentes comunidades leitoras engajaram-se com o mesmo texto a partir de questões e problemas diversos. Isto é, o texto seria inseparável desta camada de interpretações que, longe de deturparem o sentido original, contribuiriam para, na verdade, expandir o potencial dialógico do objeto literário. De forma geral, as contribuições de Jauss nos permitem analisar como a obra de Guerreiro superou a estigmatização para constituir-se como um clássico do chamado "pensamento social brasileiro", a despeito de seu lugar no universo da teoria sociológica continuar ambíguo.

Este tipo de análise, porém, não explica as disputas entre diversos grupos leitores num dado tempo comum, ou as dinâmicas institucionais e sociais que condicionam a atividade intelectual; por isto o recurso à chamada "sociologia da sociologia", que está longe de ser um campo recente nas ciências sociais. A investigação das ideias e dos textos por meio da análise dos seus condicionantes sociais e extraintelectuais está presente na obra de clássicos como Karl Mannheim, talvez o fundador da sociologia do conhecimento em sua feição moderna. Entretanto, parece difícil não localizar na obra de Pierre Bourdieu o principal fundamento para tal empreitada.

Ao procurar desmontar a oposição entre externalismo e internalismo que marcaria os estudos da cultura, Bourdieu (1996) desenvolveu o conceito de campo para averiguar os efeitos de determinação sobre a vida intelectual, fugindo ao esquema do determinismo marxista, embora retendo do mesmo o peso da variável econômica na explicação dos constrangimentos sobre a organização do mundo das ideias. Isto é, o sociólogo interessado em analisar a produção simbólica deveria atentar para a dinâmica relacional que marcaria a estruturação de posições possíveis dentro de um mercado cultural no qual os agentes concorrem por prestígio e poder. Ao mesmo tempo, as opções estéticas desses agentes deveriam ser levadas em conta, desde que investigadas a partir do espaço de possíveis produzido pelo jogo de forças dentro do próprio campo. Nesse sentido, os constrangimentos econômicos e/ou políticos se fariam valer de forma mediada, ou seja, desde que refratados pelas condições de organização interna do campo analisado.

No que se refere ao tema mais específico da construção de reputações intelectuais, a análise de Bourdieu sobre a moda (Bourdieu, 1983) mostrou como o prestígio não era um atributo pessoal, mas, sim, um efeito da crença coletiva nos objetos específicos que são disputados em cada campo. Inspirado pelos estudos de Marcel Mauss sobre o "mana", Bourdieu evidenciou o dispositivo de eficácia simbólica que governaria a atribuição de reconhecimento a um ocupante de uma posição dominante no mundo intelectual.

A obra de Bourdieu serviu de inspiração para outros trabalhos sobre organização social da atividade intelectual, que se valiam também dos desdobramentos da nova sociologia da ciência. O universo teórico relacionado ao 
tema é vasto, mas me limito aqui a discutir estratégias analíticas mais focadas na explicação da construção do prestígio intelectual. Nesse campo, destacam-se os trabalhos de Charles Camic, Michèle Lamont e Neil McLaughlin .

Em seu estudo sobre a obra de Talcott Parsons, Camic procura explicar por que o sociólogo norte-americano mobilizou apenas teóricos europeus em seu livro clássico The structure of social action, desconsiderando a então já consolidada tradição norte-americana existente. Afinal, nos seus anos de formação, Parsons teve aulas com nomes importantes do institucionalismo, que defendiam a necessidade de analisar a dimensão social e moral do agir econômico, para além do utilitarismo - um ponto crucial na obra parsoniana clássica de 1937. Ora, pergunta Camic, por que essas fontes não foram mobilizadas?

$\mathrm{O}$ argumento que explica a escolha de predecessores a partir da adequação dos conteúdos com as teses do autor que opera a seleção é descartado por Camic pois nada diz sobre por que não se escolhem determinadas teorias, mesmo elas sendo tão ajustadas como outras para o argumento encaminhado. Ao final, Camic sustenta que a escolha feita por Parsons explicava-se pela sua posição fluida no ambiente institucional de Harvard, onde pontificavam economistas liberais que criticavam severamente a escola institucionalista de Veblen, e ainda rareavam sociólogos. Isto é, em contextos com baixo acúmulo científico e relativa fluidez institucional, a importância das redes locais de interação seria muito grande para a distribuição de prestígio e credibilidade. A este artigo, o argumento interessa pela necessidade de se atentar para a forma como intelectuais e cientistas sociais constituem seu repertório de predecessores, procedimento que nada tem de óbvio e não pode ser explicado apenas pela "influência".

Mais recentemente, penso que o estudo das reputações ganhou mais densidade analítica com a contribuição de Michèle Lamont, que escreveu um conhecido artigo sobre a gênese de Jacques Derrida como um pensador francês icônico. Lamont argumenta que é preciso analisar o ajuste entre o discurso teórico feito por um autor e as condições institucionais mais amplas do mercado cultural no qual ele é consumido. No caso, ela mostra como as condições que permitiram o sucesso de Derrida na França não foram exatamente iguais àquelas que explicam sua repercussão nos Estados Unidos. Em ambos os casos, porém, ela mostra de forma convincente como é importante entender não apenas o conteúdo das ideias apresentadas nos textos, mas também os suportes institucionais, o mercado cultural mais amplo e os mecanismos de difusão que permitem produzir a legitimidade de uma teoria. O modelo analítico apresentado por Lamont foi explorado por Neil McLaughlin justamente para interpretar um estudo de caso de um "ocaso intelectual" - o do pensador alemão Erich Fromm. Explorando as diferenças entre os destinos das reputações de Derrida e Fromm, McLaughlin mostra como a ausência de nexos institucionais sólidos e os realinhamentos dos debates intelectuais sobre marxismo e psica- 
nálise nos anos 1960 contribuíram para ofuscar o papel de Fromm como intelectual reconhecido. Se antes Fromm gozara de amplo prestígio entre um público educado e urbano, a radicalização política posterior e a crescente especialização acadêmica contribuíram para deixá-lo numa posição desconfortável, sem uma "escola" com ancoragem no mundo acadêmico.

Os trabalhos de Camic, McLaughlin e Lamont evidenciam que não podemos entender o problema do ocaso intelectual como uma simples questão de superação progressiva de obras ou autores que teriam se tornados datados ou ultrapassados. Afinal, a lógica do "melhor argumento" relaciona-se às condições extra-argumentativas que governam os dispositivos de concessão de prestígio e reconhecimento no mundo intelectual.

Nesse sentido, é possível juntar as duas pontas: novas leituras ou interpretações das obras e trajetórias intelectuais devem incorporar tanto a dimensão histórico-hermenêutica, evidenciando as novas perguntas e questões que são ativadas nas releituras (ponto sustentado por Jauss), como também os mecanismos institucionais e sociais que presidem a construção de reputações. No caso deste artigo, não se trata, é preciso dizer, de buscar o "verdadeiro" Guerreiro Ramos que supostamente jaz por trás do cipoal de recepções distintas, mas de conseguir problematizar essas recepções e avançar nosso conhecimento sobre o autor por meio de um novo enquadramento - conhecimento também que é parte integrante desse cipoal hermenêutico de reputações.

\section{AS RECEPÇõES E AS REPUTAÇÕES DO GUERREIRO}

Pode-se falar em quatro grandes momentos de recepção da obra de Guerreiro Ramos: há um período inicial, contemporâneo aos seus trabalhos mais conhecidos, e que pode ser localizado entre meados dos anos 1950 e a primeira metade da década de 1960, durante o qual se registra não apenas sua conhecida polêmica com Florestan, mas também as críticas à sua sociologia feitas de uma perspectiva marxista e seu engajamento público e intelectual com a questão racial brasileira. O segundo momento se deu na segunda metade da década de 1970, quando numerosos trabalhados se orientaram para uma forte crítica do pensamento nacionalista pré-1964. O terceiro momento foi marcado pela realização do Seminário Internacional Guerreiro Ramos, ocorrido na Fundação Getulio Vargas (FGV) em 1982 - encontro este que reuniu discípulos, notórios admiradores de sua obra, estudiosos e alguns sociólogos de renome - e pela publicação dos livros de Renato Ortiz (1985) e Lúcia Lippi Oliveira (1995). Finalmente, o último momento dessa recepção se deu a partir principalmente dos anos de 1990, quando trabalhos nas áreas de Administração e Ciências Sociais voltaram seus olhos para a singularidade da produção intelectual de 
Guerreiro, reposicionando o autor no campo das ciências sociais. Minha própria pesquisa busca partir deste quarto momento.

No período inicial, a obra de Guerreiro Ramos tinha grande visibilidade pública e era motivo de resenhas e debates em revistas especializadas (em especial na revista Sociologia) e em jornais, como o Diário de Notícias e O Jornal. As polêmicas não foram poucas. A publicação de seu clássico livro sobre a redução sociológica em 1958 (Ramos, 1958) motivou dura troca com Jacob Gorender, que o criticou por conta do "subjetivismo" da filosofia existencialista utilizada e pelas "limitações" da ideologia nacionalista, que desconsideraria as contradições de classe (Gorender, 1996). Já suas teses sobre o negro brasileiro e seu próprio protagonismo na esfera pública do período ${ }^{3}$ o levaram a um forte enfrentamento com Luiz Aguiar da Costa Pinto, com quem manteve uma acirrada polêmica a respeito do estatuto da questão racial na sociedade brasileira e da própria legitimidade intelectual de Costa Pinto (Maio, 2012). Finalmente, suas teses nacionalistas sobre a sociologia foram alvo de Florestan Fernandes por ocasião do II Congresso Latino-Americano de Sociologia Latino-Americana, em 1953. Por outro lado, os escritos sociológicos de Guerreiro nos anos de 1950 também foram aplaudidos em vários setores. Benedito Nunes classificou o livro de 1958 como "[...] uma perspectiva alentadora para o desenvolvimento da filosofia no Brasil [...]", elogiando especialmente a relação entre filosofia e sociologia estabelecida pelo autor (Nunes, 1996: 200), e padre Fernando Bastos de Ávila S.J., um notório divulgador da sociologia no Brasil, saudou a "Cartilha Brasileira do Aprendiz de Sociólogo" em 1954, afirmando que "É dessas contribuições que necessita no momento a sociologia latino-americana" (Ávila S.J., 1954). O que esse conjunto de enfrentamentos e diálogos nos releva sobre a reputação inicial de Guerreiro Ramos?

Em primeiro lugar, note-se que a sua obra era lida sob o signo das polêmicas públicas, escapando a um simples debate acadêmico. O prestígio dos seus interlocutores (Florestan Fernandes, Benedito Nunes e Costa Pinto, por exemplo) indica que Guerreiro Ramos era um par reconhecido na cena intelectual, por mais que as credenciais de sua obra fossem questionadas. Além disso, é possível inferir que esse questionamento não implicava propriamente uma desqualificação total, pois a própria visibilidade pública dos isebianos era grande na época. Acrescente-se a isso o fato de que Guerreiro Ramos era percebido não apenas como um intelectual isebiano, mas também como um sociólogo com forte vinculação aos movimentos negros brasileiros, algo que não será propriamente lembrado em período posterior. Finalmente, pode-se dizer que estamos falando de um campo que ainda não estava propriamente "disciplinado" por um padrão hegemônico de trabalho intelectual, o que permitia a existência de linguagens sociológicas múltiplas e uma recepção mais diversificada da obra de Guerreiro Ramos. 
No caso da leitura eminentemente crítica, pode-se dizer que ela se firmou nos anos de 1970, e baseou-se mais propriamente numa crítica coletiva ao Instituto Superior de Estudos Brasileiros (ISEB) do que numa avaliação monográfica do personagem. Um marco desta crítica é o conhecido livro de Caio Navarro de Toledo (1978) sobre o ISEB, no qual as formulações nacionalistas do instituto são consideradas um amontoado eclético de doutrinas filosóficas que terminavam por superpor o problema da nação às contradições de classe. Esta linha interpretativa relacionava-se a um momento da cultura intelectual brasileira de forte ajuste de contas com a tradição nacionalista, momento este marcado por obras como a de Carlos Guilherme Mota (1977) e Marilena Chauí \& Maria Sylvia de Carvalho Franco (1978). De forma geral, estas obras traçavam uma história de longa duração das ideias nacionalistas no Brasil, relacionando-as a um discurso essencialista e autoritário sobre a "cultura brasileira" que terminaria por reiterar a subordinação e o quietismo do mundo popular. Neste momento, é importante ressaltar que essa comunidade leitora testemunhava o ativismo estatal da ditadura no campo da cultura, ativismo este que se baseava numa apropriação conservadora da linguagem do nacional-popular. Eram os tempos do Conselho Federal de Cultura e da tentativa de produzir políticas públicas de proteção ao folclore nacional.

Estas críticas ao ISEB guardavam forte afinidade com o hoje clássico trabalho de Dante Moreira Leite (1992) sobre o caráter nacional brasileiro. Baseado na tese de doutoramento do autor defendida em 1954, este estudo, quando publicado em 1969, ${ }^{4}$ contribuiu para consagrar uma visão negativa sobre o pensamento nacionalista em geral. Note-se, aliás, que os temas da cultura brasileira e do nacionalismo tornaram-se as grandes chaves de leitura empreendidas por esses estudos de longa duração, o que implicava enquadrar numerosos intelectuais do período entre 1930 e 1964 numa grande narrativa organizada em torno do conceito de ideologia. Ou seja, importa destacar não apenas o juízo negativo sobre a obra desses intelectuais, mas, sim, ressaltar qual a chave de leitura destacada. É por isto, por exemplo, que Franco cita brevemente Guerreiro, apenas como uma simples ilustração da frouxidão conceitual contida na teoria faseológica isebiana. No livro de Moreira Leite, Guerreiro Ramos surge como um pequeno capítulo na longa linhagem essencialista da cultura brasileira e como evidência de uma tendência mais ampla, como mostra o parágrafo seguinte:

No grupo ligado ao ISEB, convém lembrar ainda Guerreiro Ramos, ensaísta brilhante, embora frequentemente pessoal, e portanto, parcial. A sua intenção é formular uma sociologia autenticamente brasileira; no entanto, como afasta as pesquisas de pormenores, acaba por defender e justificar as interpretações amplas ou globais - do estilo das que foram examinadas nos capítulos anteriores (Leite, 1992: 320). 
Pode-se dizer que este momento da recepção contribuiu de duas maneiras para a reputação de Guerreiro Ramos na sociologia brasileira: a) fixou no cânone a vinculação ao ISEB e ao pensamento nacionalista brasileiro como variável fundamental para explicar o personagem; b) contribuiu para um juízo crítico negativo sobre a obra de Guerreiro, tida como pouco sistemática, eclética e sem os padrões de rigor que teriam emergido nos anos de 1950 e 1960. Seguindo as estratégias alinhavadas na seção anterior, é possível dizer que a obra de Guerreiro foi sendo progressivamente deixada para trás por conta da ausência de lastro na vida acadêmica e pelas próprias condições do campo intelectual brasileiro, cada vez mais especializado. O tipo de fazer sociológico que então se consolidava lançava mão de outro conjunto de predecessores, filtrados a partir da linha evolutiva que se imaginava ser a principal a organizar a moderna ciência social feita no país (Lahuerta, 1999).

O processo de resgate da reputação de Guerreiro contribuiu para questionar esses dois pressupostos, embora este trabalho ainda não esteja totalmente completo. Um marco inicial se dá com sua reaproximação da vida intelectual e política brasileira, no final dos anos 1970. Ele volta a contribuir para jornais nacionais, como o Jornal do Brasil, envolve-se na tentativa de montar um programa de pós-graduação na Universidade Federal de Santa Catarina, e vem ao Rio de Janeiro para participar de Seminário sobre a Revolução de 1930 realizado na Fundação Getulio Vargas.

Esse resgate não é interrompido por sua morte. No ano de 1982, é organizado pela Escola de Administração da Fundação Getulio Vargas um simpósio internacional em sua homenagem. Este seminário resultou na publicação de várias contribuições editadas na Revista de Administração Pública no ano de 1983, um marco importante na tentativa de reverter o processo de deslegitimação de Guerreiro Ramos.

O evento incluía principalmente discípulos de Guerreiro Ramos, em especial ex-alunos e professores da University of Southern California, além de profissionais da FGV que conviveram com o sociólogo baiano. O evento foi dividido em cinco painéis, e é notável a diferença entre as avaliações feitas pelos entusiastas de suas obras, que celebram Guerreiro como "[...] intelectual notável, talento versátil, emérito fumador de charutos e tomador de chimarrão" (Matta, 1983: 95) e o consideram dotado de uma prosa absolutamente singular, pois nela "[...] pode-se encontrar um tal ritmo poético que torna, às vezes, a tradução para outras línguas somente possível com alguns danos ao seu pensamento original" (Garcia, 1983: 121), e as análises mais sóbrias e mesmo desconfiadas, elaboradas por representantes do mainstream acadêmico de então, como Simon Schwartzman e Bolívar Lamounier. Ambos fazem elogios à obra guerreiriana, mas se mostram céticos quanto a alguns de seus aspectos teórico-metodológicos, evidenciando proximidades com a interpretação empreendida pela comunidade leitora paulista da década de 1970. Schwartzman, por 
sinal, é enfático ao afirmar que "A obra de Guerreiro Ramos é principalmente crítica, mas de poucos resultados. Ele não prezava o trabalho intelectual enquanto tal, e seu projeto político, por razões históricas que conhecemos, não foi muito adiante" (Schwartzman, 1983: 32).

$\mathrm{Na}$ medida em que a história das ciências sociais se consolidou como um campo específico, confundindo-se, muitas vezes, com a própria área de pensamento social brasileiro, outros trabalhos emergiram. Pode-se dizer que o juízo crítico mais consagrado a respeito do lugar do ISEB e de Guerreiro Ramos na história intelectual nacional está registrado na obra coletiva História das ciências sociais no Brasil, organizada por Sérgio Miceli (1989a). O artigo do próprio Miceli constrói uma comparação entre a sociologia no Rio e em São Paulo a partir das diferenças existentes no processo de institucionalização acadêmica (Miceli, 1989b). Enquanto no Rio a sociologia teria permanecido como um saber disperso, praticado por diletantes de origens sociais elevadas, em São Paulo a consolidação da USP teria sido responsável pela rotinização de um padrão de trabalho intelectual mais disciplinado e rigoroso, engendrando um campo acadêmico mais autônomo em relação à política. Nesta interpretação, a sociologia carioca viria a ser metonimizada pelo ISEB, contribuindo, mais uma vez, para resumir a trajetória de Guerreiro a este aparato específico.

Os primeiros sinais de uma nova leitura de Guerreiro Ramos no campo das ciências sociais são evidenciados por dois movimentos. Por um lado, pela edição do livro de Renato Ortiz sobre cultura brasileira e identidade nacional (Ortiz, 1985). Por outro, pelo trabalho feito por Alzira Abreu e Lúcia Lippi sobre sua obra. No caso de Ortiz, seu livro analisava o ISEB em um capítulo, no qual dialogava com as interpretações então hegemônicas de Carvalho Franco e de Toledo. Embora reconhecesse o acerto dessas críticas na análise dos problemas teóricos da produção isebiana, Ortiz argumentava que não se poderia qualificar esse pensamento como uma ideologia hegemônica que tivesse organizado as elites dirigentes do período. Nesse sentido, desvincula o ISEB do argumento "fábrica de ideologias". Ao mesmo tempo, o sociólogo paulista recuperava o estatuto teórico da obra dos intelectuais isebianos ao situar essa produção no campo global do pensamento anticolonial, com destaque para as obras de Balandier e Fanon. Com esse movimento, Ortiz resgatava, também, Guerreiro Ramos do limbo intelectual a que fora jogado, conferindo-lhe mais relevância como pensador.

O grupo radicado no Centro de Pesquisa e Documentação em História Contemporânea do Brasil (CPDOC) da FGV, e que também participara do seminário de 1982, navegava em caminho similar. Alzira Alves de Abreu (1975) fora uma das primeiras estudiosas do ISEB, mas sua tese de doutoramento, originalmente escrita em francês, não comungava do diagnóstico corrosivo de Toledo, e de Carvalho Franco e Chauí. Seu trabalho analisava a dinâmica organizacional, política e ideológica do Instituto, mas concluía que seu ocaso se devia mais a 
mudanças na composição das elites dirigentes, processo deslanchado pelo desenvolvimentismo burocrático de Juscelino Kubitschek. Nesse quadro histórico, os técnicos teriam deslocado o protagonismo das elites de formação humanista, que seriam características do ISEB. A despeito de sua qualidade, o trabalho de Alzira Abreu permanece inédito em português até hoje, embora seja referência para especialistas e pesquisadores do tema.

Já o livro de Lúcia Lippi de Oliveira, outra participante do CPDOC no seminário da FGV, deve ser visto como o aríete que abriu caminho para uma onda de novos artigos e teses sobre o personagem no campo das ciências sociais, em especial na área de estudos intitulada pensamento social brasileiro. Em seu livro, Oliveira construiu vários capítulos autônomos, em que analisa a biografia intelectual de Guerreiro Ramos, sua inserção geracional na cidade de Salvador e posterior experiência política no Rio, além de empreender cuidadosa leitura interna dos grandes textos do autor. O livro também foi responsável por conferir grande destaque à experiência religiosa de Guerreiro e sua relação com seu projeto sociológico. Enfim, pode-se dizer que a obra de Oliveira contribuiu para conferir dignidade intelectual ao sociólogo baiano, além de providenciar outras chaves de leitura que não a equação "ISEB-sociologia nacionalista". De certa maneira, é um trabalho que pode ser considerado ponto de passagem entre o terceiro momento da recepção - marcado pelo Seminário da FGV - e o mais recente, pautado pelos trabalhos acadêmicos sobre o autor publicados em programas de pós-graduação.

Este movimento de transição foi acompanhado pela reedição de algumas de suas principais obras pela editora da Universidade Federal do Rio de Janeiro (UFRJ), com comentários, introduções e notas. O cientista político Clóvis Brigagão, ex-aluno de Guerreiro Ramos na Escola Brasileira de Administração Pública e de Empresas (EBAPE/FGV), foi figura fundamental nesse processo, e escreveu prefácio para a edição de 1995 de Introdução crítica à sociologia brasileira (Ramos, 1995), que continha também um breve ensaio de Joel Rufino intitulado "O negro como lugar" (Rufino, 1995). No ano seguinte, publicava-se a terceira edição do clássico A redução sociológica (Ramos, [1958] 1996), também pela editora da UFRJ, com breve apresentação de Brigagão e a adição do prefácio presente na segunda edição da obra, escrito em 1963 pelo próprio Guerreiro. A orelha desta terceira edição continha breves linhas assinadas por Abdias do Nascimento, Celso Furtado, Gilberto Paim e Nanci Valadares de Carvalho.

Como forma de melhor compreender o último momento na recepção da obra de Guerreiro e as disputas em torno de sua reputação intelectual, mobilizei duas fontes bibliográficas: o Banco de Teses da Coordenação de Aperfeiçoamento de Pessoal de Nível Superior (CAPES), que contempla produções a partir de 1987, e nem sempre é tão completo, e a relação bibliográfica feita por Ariston Azevedo e publicada como anexo em sua tese de doutoramento em 2006 (Azevedo, 2006). É claro que estas duas fontes não esgotam totalmente o 
mapeamento, e procurei complementá-las consultando as citações e referências feitas em trabalhos acadêmicos sobre o autor. Meu objetivo era averiguar, em especial, o período a partir dos anos 1990.

Uma primeira inferência permitida pela análise destas fontes diz respeito à diferença de recepção e prestígio nos campos da Administração e das Ciências Sociais. No caso da primeira área, são comuns teses e dissertações que utilizam Guerreiro Ramos como referencial teórico para estudos empíricos. A primeira referência encontrada foi para o ano de 1990, e a partir de meados da primeira década do século XXI há um surto de trabalhos que utilizam como marco analítico a teoria da delimitação dos sistemas sociais, em especial nas universidades no Sul do Brasil (como a Positivo e a Federal do Rio Grande do Sul), e em algumas no Nordeste, como as Universidades Federais do Rio Grande do Norte, da Bahia e de Pernambuco.

No caso das ciências sociais, Guerreiro surge principalmente como objeto de estudo, em especial em teses e dissertações difusamente organizadas na rubrica do pensamento social brasileiro. São poucos os trabalhos defendidos na década de 1990 centrados exclusivamente em Guerreiro - o único com esse perfil é o de Elizabeth Rago (1993), já que Virgílio de Oliveira Filho (1993) e Vânia Noeli de Assunção (1999) discutem Guerreiro de forma subsidiária em estudos sobre nacionalismo e ideologia -, mas a partir dos anos 2000 surgem vários trabalhos monográficos. Cito os casos de Márcio Ferreira de Souza (2000) - posteriormente lançado em livro -, José Saraiva Cruz (2002), Muryatan Barbosa (2004), Aparecida Abranches (2006), Ariston Azevedo (2006), Andréa de Amorim (2008) e Edson Bariani Junior (2008). Além disso, há trabalhos sobre a polêmica entre Florestan Fernandes e Guerreiro, um dos eixos analíticos principais utilizados para se analisar a história das ciências sociais no Brasil e nela o lugar do nosso personagem. São os casos de Bariani Junior (2003), Mário Hecksher (2004), Tatiana Martins (2008) e Ricardo Shiota (2010).

A leitura dos resumos e dos trabalhos completos evidencia uma mudança na reputação de Guerreiro, não mais visto como um sociólogo "pouco rigoroso", espécie de fracassado antagonista intelectual de Florestan. Trata-se, agora, de uma leitura mais matizada, que procura levar em conta a dinâmica interna dos textos guerreirianos e evidenciar nexos analíticos mais amplos que aqueles que redundaram na visão negativa consolidada no segundo momento de recepção. Neste campo, pode-se citar também o estudo de Marco Chor Maio (1997), que localiza as contribuições e atitudes de Guerreiro no campo dos estudos raciais, analisando seus debates com Luiz Aguiar da Costa Pinto. O trabalho de Maio relaciona-se a uma preocupação em rastrear com mais cuidado histórico passagens específicas do trabalho intelectual de Guerreiro.

É possível dizer que a releitura da obra de Guerreiro é indissociável de um movimento de releitura da própria produção isebiana, que emergia ainda na esteira da leitura crítica feita ao longo dos anos 1970. Alguns livros pionei- 
ros desse movimento foram os de Vanilda Paiva (1980), Daniel Pécaut (1990) e, mais recentemente, Luiz Eduardo Motta (2000), além da coletânea editada pelo próprio Caio Navarro de Toledo (2004), na qual críticos notórios e ex-membros do próprio Instituto fazem avaliação mais equilibrada do legado isebiano. Notável, aliás, o artigo do próprio Navarro de Toledo, no qual o autor, a despeito de classificar o ISEB como um "aparelho ideológico de Estado", destaca a conexão do Instituto com as forças progressistas e democráticas do período. $\mathrm{Na}$ nota 37, que finaliza seu texto, ele busca equilibrar os dois tempos de sua própria recepção, afirmando:

[...] o presente artigo, com um outro objetivo analítico, buscou - como desejavam e reivindicaram alguns críticos de meu livro - ressaltar a atuação política progressista e democrática desempenhada pelo Instituto no interior da sociedade brasileira dos anos 1960. Não se trata, pois aqui de "reabilitar" o ISEB, mas de ressaltar que uma avaliação criteriosa e rigorosa de seu significado e relevância (ou não) no interior da formação cultural brasileira dos anos 1950 e 1960 impõe que a contextualização histórica e política da instituição seja devidamente levada em consideração (Toledo, 2004: 164).

Entre os autores resgatados neste movimento geral de releitura, destacam-se Álvaro Vieira Pinto - que nunca deixou de frequentar a bibliografia dos estudiosos da educação, por conta da sua alegada influência sobre Paulo Freire -, Nelson Werneck Sodré (alvo de recente interesse acadêmico, após décadas de ostracismo) e Hélio Jaguaribe. São exemplos desta discussão o trabalho de Norma Cortes (2003) sobre Vieira Pinto, que no seu primeiro capítulo situa exatamente a fratura existente entre os diferentes tempos de recepção da produção do ISEB, enfatizando o apogeu das leituras estruturalistas na filosofia e o declínio de perspectivas existencialistas e historicistas. O prefácio escrito por César Guimarães - figura central neste movimento, por orientar numerosos trabalhos sobre intelectuais dos anos 1950 no antigo Instituto Universitário de Pesquisas do Rio de Janeiro (IUPERJ) - destaca exatamente a existência de "dois tempos" da recepção da obra de Guerreiro Ramos: a produção do "cânon" (momento da crítica de Chauí, Carvalho Franco e outros) e a superação do mesmo. No seu registro, "A nova leitura, a que se filia este trabalho de Norma Côrtes, opera em outro contexto político e intelectual. Trata-se menos de produzir evidências que invalidem ou parcialmente limitem conclusões do cânon - embora isso também caiba -, mas de situá-las no tempo. Datá-las" (Guimarães, 2003: 16).

Este movimento de releitura da obra de Guerreiro completou-se, de certa maneira, com a tese de Ariston de Azevedo (2006), talvez o mais completo retrato biográfico-intelectual do personagem, no qual são analisadas suas fontes intelectuais, sua imersão poético-literária, seu treinamento filosófico num seminário no Rio, suas experiências no Departamento Administrativo do Serviço Público (DASP), seu período isebiano e, principalmente, os trabalhos associados à teoria da administração. 
O que podemos afirmar sobre este último momento de recepção? Sustento que esta veia interpretativa contribuiu para duas alterações na produção da reputação intelectual de Guerreiro Ramos: a) mais atenção ao personagem e sua trajetória, para além de sua vinculação isebiana; b) mais cuidado com as sutilezas de seu pensamento e de seus escritos, inventariando fontes, formação filosófica, conversão religiosa etc.

Há uma dimensão hermenêutica óbvia na mudança da reputação de Guerreiro, já que as interpretações que começaram a proliferar nas décadas de 1990 e 2000 eram motivadas por uma nova visada sobre o significado do nacionalismo dos anos 1950 e 1960. Este novo olhar relacionava-se também a uma mudança no ambiente político-intelectual, caracterizado pela reação ao aprofundamento das reformas liberais no país e por uma consequente reavaliação positiva do regime de 1946 . Vale lembrar que foi nesse momento que, no campo da História, a crítica ao conceito de populismo ganhou corpo, por intermédio dos trabalhos de Jorge Ferreira e Angela de Castro Gomes, consubstanciados na coletânea O populismo e sua história: debate e crítica (Ferreira, 2001). Ou seja, vivia-se um momento de releitura positiva da experiência outrora desqualificada.

A despeito dessa mudança no horizonte hermenêutico, que alterou o estatuto dos intelectuais ligados ao ISEB, decerto há diferenças de leitura mesmo dentro desse novo tempo, que podem ser explicadas por diferentes configurações dos próprios mercados acadêmicos, ponto fundamental afirmado pela sociologia das reputações, em especial por Lamont. No campo da Administração, o estatuto de Guerreiro como teórico e formulador original foi preservado, mas no campo das ciências sociais, seu lugar de outsider, espécie de profeta da sociologia nacionalista, resistiu como uma classificação relevante. Ou seja, Guerreiro Ramos ainda surge mais como um objeto de interesse sociológico do que como um clássico de direito da própria sociologia brasileira, como o é Florestan Fernandes, por exemplo. Penso que tanto o seminário organizado pela FGV em 1982, como a análise do Banco de Teses, são ilustrativos desta diferença. O primeiro evidenciou dissonâncias entre as percepções de teóricos da administração e cientistas sociais, traduzindo o estado do campo das ciências sociais de então, que conheceram sua profissionalização lançando mão de outros predecessores reconhecidos como balizadores de qualidade. O Banco de Teses reforçou esta inferência, ao mostrar o lugar de Guerreiro como objeto de investigação, mas não propriamente como um teórico ou um clássico da sociologia.

Ou seja, a recente recepção certamente contribuiu para mudar o juízo crítico a respeito do autor, resgatando-o do limbo da ausência de rigor e do ecletismo a serviço do capital e da ideologia nacionalista. Entretanto, ainda há trabalho historiográfico a ser feito. Uma forma de melhor compreender a obra 
guerreiriana é inscrevê-la no debate mais amplo da sociologia global entre os anos de 1950 e 1980, procedimento sugerido por Renato Ortiz em 1985 e seguido por alguns estudiosos nos anos subsequentes. Esse procedimento analítico permitiria restaurar a dignidade teórica do autor sem necessariamente cairmos numa exegese singularista. Ao mesmo tempo, a inscrição de Guerreiro num universo intelectual mais amplo possibilita a apreensão dos nexos entre suas ideias e debates internacionais, evitando, portanto, a reiteração do nacionalismo e do isebianismo como chaves principais de leitura de sua obra.

\section{O GUERREIRO E A SOCIOLOGIA}

Sigo aqui três estratégias de leitura. Inicialmente, concentro-me nas primeiras publicações sociológicas de Guerreiro, em especial seus artigos na Revista de Saúde Pública. Nesses escritos, pode-se ver o quanto o autor estava atualizado em relação ao cânone disciplinar que então começava a se montar nos Estados Unidos, com a incorporação da teoria europeia (Weber, Durkheim), a preservação da tradição ecológica de Chicago e o desenvolvimento das técnicas de pesquisa empírica que marcariam a sociologia norte-americana no pós-Segunda Guerra Mundial. Em seguida, mostro como mesmo a produção sociológica de Guerreiro sobre nacionalismo e sociologia pode ser relacionada a debates fundamentais para a universalização da disciplina entre os anos de 1950 e 1980. Finalmente, chamo a atenção para os textos publicados por Guerreiro Ramos depois de 1964, quando parte para os Estados Unidos e concentra-se em temas do universo administrativo. Esses escritos, raramente mobilizados pelos cientistas sociais, embora bem analisados pelos estudiosos da Administração, relevam um intelectual absolutamente consciente dos debates globais da disciplina, bem como dos temas que mobilizavam tanto a imaginação europeia, marcada pela teoria crítica e seus desdobramentos, como a imaginação pós-positivista nos Estados Unidos. Em ambos os casos, valho-me do rastreamento de citações como instrumento metodológico de aferição dos padrões de comunicação intelectual do autor.

A reputação de Guerreiro como um sociólogo nacionalista pouco afeito aos rigores da ciência especializada não resiste a uma atenta leitura de sua produção feita nos anos de 1940. Nas páginas da revista ligada ao DASP, o sociólogo baiano escrevia sobre temas típicos do mainstream sociológico de então: controle social, níveis de vida, criminalidade e burocracia. As referências teóricas que aparecem com maior destaque nos seus escritos são Max Weber - alvo de conhecida resenha introdutória, uma das primeiras feitas no Brasil - e Karl Mannheim.

No artigo "Administração e política à luz da Sociologia" (Ramos, 1946a) Guerreiro vale-se de uma interpretação do conceito de racionalidade na obra 
de Mannheim para sugerir uma agenda de preparação intelectual dos futuros daspianos centrada em autores clássicos como Weber, Durkheim e Simmel. Já em "A sociologia de Max Weber (teoria e prática da administração)" (Ramos, 1946b), Guerreiro faz uma apresentação crítica da obra de Weber, tomando como fontes as traduções mexicanas de Economia e sociedade e História econômica geral, além da versão americana da Ética protestante e o espírito do capitalismo, na tradução de Talcott Parsons. Na literatura secundária, surge não apenas Parsons, mas também outros comentadores weberianos, como Solomon, Echavarría e Bendix. Outros artigos expõem também grande domínio de tradições sociológicas então em voga na disciplina. É o caso de estudo dedicado à obra de W. I. Thomas (Ramos, 1948a), ou de um balanço bibliográfico sobre aculturação e assimilação (Ramos, 1948b), no qual constam autores como W. F. Ogburn, Donald Pierson, Robert Redfield, Melvin Herskovits, Thomas \& Znaniecki, Emilio Willems, entre outros.

Mesmo se nos restringirmos aos textos mais conhecidos de Guerreiro, escritos entre 1952 e 1963, é possível verificarmos que eles não são apenas tributos ao nacionalismo brasileiro do período, conectando-se ao pensamento anticolonial em geral (Fanon, Césaire, Moussa etc.) e ao campo global da sociologia periférica entre os anos de 1950 e 1980. Nesse campo, diferentes revistas, obras e intelectuais buscavam absorver criticamente a produção sociológica exportada no pós-1945 e reinventar a linguagem da sociologia do desenvolvimento. Assim, a produção de Guerreiro deve ser vista como estando sintonizada com os escritos de nomes como o do argelino Anouar Abdel-Malek (1963) e do malaio Syed Hussein Alatas $(1956 ; 1972)$. Este último, por exemplo, também partira da obra de Karl Mannheim para construir um discurso sociológico pautado pela análise crítica do consumo de conceitos oriundos da experiência europeia e sua aplicação irrefletida e/ou ingênua em países periféricos. Não à toa, em seu texto mais famoso, no qual apresenta o conceito de "mente cativa" (Alatas, 1972), ele cita as obras de Celso Furtado e Raul Prebisch como fontes teóricas para seu ataque ao que acreditava ser o colonialismo mental. Em textos dos anos de 1950, Hussein Alatas (1956) analisava a religião islâmica utilizando o arsenal disponível da sociologia histórica, enfatizando o problema acarretado pela utilização acrítica do conceito de "religião", tido como excessivamente vinculado à experiência europeia. Abdel-Malek, por sua vez, escrevera, no começo dos anos 1960, um célebre artigo crítico sobre o Orientalismo, evidenciando o viés eurocêntrico presente nos estudos de área que então grassavam nas ciências sociais.

Estes pensadores são apenas exemplos de um horizonte transnacional das ciências sociais nos quais Guerreiro se inscrevia, juntamente com outros cientistas sociais latino-americanos. Este horizonte se refletia nos textos do sociólogo baiano por intermédio de categorias que estavam longe de serem faturas singulares do universo intelectual brasileiro, e também por intermédio 
de citações a autores que circulavam como referências para o pensamento anticolonial do período. No que se refere às categorias da sociologia periférica, refiro-me a termos como "mentalidade colonial" e "periferia ocidental", que surgem nos primeiros capítulos do clássico livro de 1958, secundadas por citações de autores como Anta Diop, Aimé Césaire e Mohamed Lahbadi. De maneira geral, esta inscrição se traduzia na própria forma do texto também, pois implicava traduzir a herança intelectual do personalismo francês - um dos traços mais persistentes no pensamento de Guerreiro Ramos - no vocabulário anticolonial. Assim, por exemplo, a seção intitulada "A mentalidade colonial em liquidação" apresenta uma leitura personalista da emergência da consciência crítica - tema originalmente pensado a partir de uma filosofia existencialista do sujeito - nos quadros de uma leitura da situação periférica do Brasil, que destacava o "povo" como categoria histórica. Não à toa, a única referência apresentada é do marroquino Lahbadi, outro autor também versado na tradição do personalismo filosófico.

Finalmente, é possível dizer que este ambiente transnacional também explicava por que o texto de Guerreiro Ramos e de outros autores não-brasileiros, como o supracitado Hussein Alatas, partilhavam algumas categorias discursivas. O caso das ideias cepalinas constitui um bom exemplo. Segundo entrevista concedida pelo próprio autor (Oliveira, 1995), essas ideias foram fundamentais para o equacionamento de sua visão sobre a industrialização brasileira, presente na primeira parte do livro sobre a redução sociológica. Como já mostrou Joseph Love (1998), teorias sobre autonomia econômica e industrialização circulavam em diversos países periféricos antes de ganhar forma definitiva no pensamento cepalino, sendo depois recepcionadas no continente asiático e em outros contextos.

É possível dizer que este ambiente transnacional era um campo cognitivo - embora não formalmente estruturado como um campo no sentido bourdiano - pautado, em parte, pela reação crítica à exportação global da sociologia funcionalista de corte parsoniano, como já apontou Antônio Brasil Junior (2011). Esses intelectuais mobilizavam sociologia, economia do desenvolvimento, marxismo e fenomenologia para pensar problemas da sociologia histórica a partir de suas condições periféricas. Desenvolvimento, dependência, imperialismo, mente cativa, alienação e autonomia eram alguns dos conceitos-chave desse campo que, embora alvo de pesquisas isoladas, nunca foi estudado em sua integridade, sendo usualmente esquecido nos compêndios de história da sociologia e da teoria social. A história da sociologia nos informa que esse período teria sido marcado somente pela consolidação do estrutural-funcionalismo e pela sua posterior crítica a partir das teorias de conflito desenvolvidas na Europa e nos Estados Unidos (Joas \& Knobl, 2009). É por este motivo que as releituras de Guerreiro Ramos terminam por situá-lo a contrapelo do desenvolvimento da ciência sociológica. Ora, se reconhecermos que a sociologia foi formada por tradições 
intelectuais alternativas, que dialogavam com problemas e conceitos centrais para a disciplina, mas de perspectivas periféricas, fica mais fácil "desprovincializar" o sociólogo baiano. Afinal, a inscrição de Guerreiro Ramos no ambiente global da sociologia tal como praticada no Sul Global entre os anos de 1950 e 1980 evidencia que ele estava longe de ser um outsider ou uma espécie de profeta descolado de tendências mais gerais do pensamento sociológico do período.

A categoria de Sul Global tem aqui sentido amplo, designando o conjunto de sociedades periféricas que foram marcadas, em diversos graus, pelas experiências do colonialismo e do subdesenvolvimento. A expressão tem uma história recente, mas a percepção subjacente de uma profunda assimetria na geopolítica global (no caso, entre Sul e Norte) reitera uma visão já disponível em outras categorias utilizadas nos anos pós-Segunda Guerra, como "periferia" ou "subdesenvolvidos". O fato fundamental a reter aqui é que esta situação histórica das sociedades marcadas pelo colonialismo traduzia-se numa condição intelectual periférica, que trazia para o centro dos discursos sociológicos conceitos como "mentalidade colonial", "dependência" e "Orientalismo".

Mais recentemente, esforços teóricos foram feitos para sistematizar o que seria esta condição. O exemplo mais bem acabado desses esforços está no livro de Raewyn Connell (2007) sobre o que a autora chama de "southern theory" (teoria do Sul). Ao analisar como diversos sociólogos oriundos de países do Sul Global estruturaram suas reflexões sobre os dilemas modernos, Connell argumenta que o colonialismo, este fenômeno quase ausente na reflexão teórica clássica, converteu-se em tema principal para boa parte dos intelectuais deste canto do hemisfério. Neste sentido, pode-se dizer que o Sul Global, a despeito se não ser um conceito que traduza propriamente um campo intelectual estruturado, designa, sim, uma condição histórico-intelectual que nos permite inscrever o pensamento de Guerreiro Ramos à luz de uma situação que era, por natureza, extranacional.

Uma questão correlata que está no horizonte futuro da pesquisa diz respeito à possibilidade de rastrear viagens, deslocamentos, traduções de obras e outras experiências "físicas" de migração de ideias que permitam aferir a dimensão empírica da circulação destas no Sul Global. Alguns estudos recentes vêm destacando como certas teorias e conceitos foram gestados a partir de dinâmicas transnacionais que não seguiam a rota clássica Norte-Sul, mas sim Sul-Sul, e certamente servirão de subsídio para a análise proposta (Pinheiro, 2010; Beigel, 2010).

Finalmente, vale a pena reabrir os últimos escritos de Guerreiro Ramos, produzidos durante seu exílio norte-americano. Tomemos como exemplo o livro Administração e estratégia de desenvolvimento (Ramos, 1966), escrito graças à acolhida recebida pelo autor na Fundação Getulio Vargas após o golpe militar. No capítulo 5, intitulado "Burocracia e estratégia de desenvolvimento", Guerreiro mobiliza não apenas Max Weber, mas autores como Talcott Parsons, Rei- 
nhart Bendix e Robert Dahl para discutir o problema da burocracia e da poliarquia, além de empreender análise crítica da sociologia da modernização, que conhecera seus dias de glória na década de 1960 e vinha sendo fortemente criticada na segunda metade dos anos 1960 (Brasil Junior, 2011). Como se vê, mesmo em condições de precária inserção institucional, Guerreiro lograva manter-se atualizado com a discussão teórica das ciências sociais, em especial aquelas impulsionadas pela hegemonia da ciência política norte-americana.

A edição traz dois apêndices. No segundo, Guerreiro debate diretamente com um artigo de Parsons publicado em 1964 na American Sociological Review. No texto, o sociólogo brasileiro analisava o uso das variáveis-padrão como universais evolucionários, apontando os ganhos analíticos da construção parsoniana e os problemas de sua naturalização a-histórica. Sustentava, ao final, que a consideração abstrata de variáveis modernizadoras prejudicava a compreensão dos mecanismos históricos particulares que governavam a ação coletiva nos países periféricos. Percebe-se, portanto, que Guerreiro estava conectado aos debates atuais do campo, e acompanhava detidamente a produção recente, pois tomara como fonte para sua análise um dos artigos mais recentes de Parsons, publicado na revista que, ainda hoje, lidera o universo da sociologia norte-americana. Esta sintonia evidenciava-se também no caso brasileiro, pois o capítulo mobiliza os trabalhos de Fernando Henrique Cardoso, Juarez Brandão Lopes e Vieira da Cunha para discutir as relações entre modernização industrial no Brasil e o deslocamento da ordem patrimonialista - tema, como se sabe, central na reflexão uspiana.

Guerreiro também se inscreve no debate sobre as dimensões patológicas da racionalidade ocidental, tema caro não apenas à teoria crítica de extração alemã, mas também a boa parte da própria sociologia dos anos de 1960 e 1970. Esta incursão é visível em artigos do começo dos anos 1970, como "A nova ignorância e o futuro da administração pública na América Latina" (Ramos, 1983a) (a conferência foi feita em 1970, mas publicada em português apenas em 1983), no qual mobiliza Hegel, Dewey e Erich Fromm para pensar as relações entre burocracia e alienação. Em "A teoria administrativa e a utilização inadequada de conceitos" (Ramos 1983b), volta ao tema, desta vez criticando o uso rebaixado que teóricos americanos da administração faziam do conceito marxiano de alienação. O artigo era resultado de conferência feita em 1972.

Em sua última obra, intitulada ambiciosamente A nova ciência das organizações: uma reconceituação da Riqueza das Nações (Ramos, 1981), Guerreiro revisita sua bagagem filosófica, em especial suas leituras do personalismo cristão e da filosofia aristotélica, articulando-as a discussão sociológica e filosófica contemporânea de sua época. O argumento do livro gira em torno da crítica à limitação da razão individual por conta das exigências sistêmicas de uma sociedade fundada no mercado, tema comum ao pensamento sociológico do período. Entretanto, Guerreiro vai além, pois busca vincular esta dinâmica 
à emergência das próprias ciências sociais, que teriam seu discurso fundado na subordinação da razão como atributo substantivo dos indivíduos e na eleição da racionalidade instrumental como esfera coordenadora da integração social. Trata-se, portanto, de um debate mais propriamente filosófico, que busca articular a crítica do capitalismo tardio a uma reflexão epistemológica sobre o estatuto do próprio conhecimento sociológico. Como se vê, estamos em território cujas afinidades com a teoria crítica são evidentes.

Não se trata aqui de resenhar a obra, que ainda está por merecer um trabalho de exegese potente no campo do pensamento brasileiro e da teoria sociológica, mas apenas apontar os indícios de atualização teórica do autor. A discussão que empreende entre racionalidade substantiva e formal não remete apenas a Mannheim, mas também às obras de Adorno, Horkheimer e Habermas. Apenas na bibliografia do capítulo 1, estão citados Eclipse of reason, de Horkheimer (edição da Oxford University, de 1947), a edição americana da Dialética do esclarecimento, de 1972, e as edições da Beacon Press de duas obras fundamentais de Habermas: Knowledge and human interests, de 1971, e Theory and practice, de 1973.

No capítulo 6, Guerreiro lança-se a um esforço de historicização do mercado como instituição humana, e baseia-se em Marcel Mauss e Karl Polanyi. Ao sustentar a inscrição simbólica do mercado em relações sociais mais amplas, a literatura mobilizada é própria do interacionismo simbólico, como Georg Mead, mas há espaço também para Herbert Blumer, Ernst Cassirer e Habermas, novamente. Sua discussão interacionista, por sinal, remete muito à leitura habermasiana da ação comunicativa, entendida como esfera de coordenação que não pode ser subsumida a considerações pragmática de eficácia.

Percebe-se, portanto, que estamos distante da sociologia nacionalista que marcou boa parte da recepção de Guerreiro Ramos na história das ciências sociais nacionais. Se a primeira fase de sua produção evidencia um interesse grande nas discussões metodológicas feitas nas ciências sociais norte-americanas, num movimento que encontrava eco em outros lugares da América Latina, sua fase tardia mostra um notável parentesco com debates originados no campo da teoria crítica europeia. E, mesmo sua fase intermediária e mais conhecida, pois relacionada ao seu breve período isebiano, ganha em relevância analítica quando inscrita num capítulo específico da imaginação sociológica global.

Este não é um retrato final e definitivo de Guerreiro Ramos, mas apenas um esforço analítico novo que visa situar a obra deste autor no enquadramento do desenvolvimento do discurso sociológico propriamente dito. Longe de negar contribuições anteriores, este esforço vale-se muito delas, pois considero que a recepção mais recente da obra de Guerreiro nos permitiu visualizar chaves interpretativas até então não muito exploradas. Resta, porém, muito a ser feito neste projeto. Em última instância, trata-se de inscrever a dinâmica 
do pensamento brasileiro numa marcação transnacional, evidenciando o quanto a dinâmica das ideias em nossa sociedade pode ser entendida à luz de processos mais gerais que ocorriam não apenas nas periferias, mas na própria metrópole. Em tempos de realinhamento global e da ascensão dos ditos países emergentes, creio não haver tarefa mais urgente do que esta.

Recebido para publicação em janeiro de 2012.

João Marcelo E. Maia é professor adjunto de Sociologia no Centro de Pesquisa e Documentação de História Contemporânea do Brasil (CPDOC) da Escola Superior de Ciências Sociais da Fundação Getúlio Vargas (FGV). É doutor em Sociologia pelo Instituto Universitário de Pesquisas do Rio de Janeiro (Iuperj) da Universidade Candido Mendes (UCAM) e atua nas áreas de pensamento social brasileiro e sociologia da cultura. É autor de A terra como invenção: o espaço no pensamento brasileiro (2008). 


\section{NOTAS}

1 Agradeço à Fundação de Amparo à Pesquisa do Estado do Rio de Janeiro (FAPERJ), que financiou o projeto "Terra, autonomia e imaginação periférica: descentrando o pensamento social brasileiro", por meio de seu edital APQ1 de 2010. Este artigo é parte desse projeto.

2 Não me refiro aqui à "história da sociologia" como subcampo acadêmico, no qual são feitos numerosos trabalhos exatamente sobre o processo histórico de produção dos clássicos, mas, sim, ao modo naturalizado com que cursos de formação se organizam. Esta naturalização reflete-se no pouco questionamento que os cientistas sociais fazem a respeito da literatura tida como clássica.

3 Guerreiro Ramos foi personagem central na organização do I Congresso do Negro Brasileiro em 1950, além de publicar artigos e textos sobre a questão racial brasileira. Sua amizade com Abdias do Nascimento o levou a ser um militante do Teatro Experimental do Negro, sobre o qual discorria com frequência em entrevistas e artigos na primeira metade da década de 1950.

4 O livro de Dante teve um caminho curioso: após sua publicação numa edição do Boletim da FFCLH de 1959, o texto só foi ser editado na forma de livro em 1969, ganhando uma reedição em 1976 e uma quarta edição "definitiva" em 1983, com apresentação de Alfredo Bosi.

\section{REFERÊNCIAS BIBLIOGRÁFICAS}

Abdel-Malek, Anouar. Orientalism in crisis. Diógenes, 1963, 11/44, p. 103-140.

Abranches, Aparecida Maria. Nacionalismo e democracia no pensamento de Guerreiro Ramos. Tese de doutorado. Instituto Universitário de Pesquisas do Rio de Janeiro/Universidade Candido Mendes, 2006.

Abreu, Alzira Alves de. Nationalisme et action politique au Brésil: une étude sur l'ISEB. Thèse de Doctorat de 3ème Cycle. Université René Descartes, 1975.

Alatas, Syed Hussein. The captive mind in development studies. International Social Science Journal, 1972, 34/1, p. 9-25. 
Democracy of Islam: A concise exposition with comparative reference to western political thought. Haia: W. Van Hoege Bandung, 1956.

Amorim, Andrea Estevam de. A saúde sob a perspectiva da sociologia. Textos inéditos de Guerreiro Ramos sobre puericultura e mortalidade infantil. Tese de doutorado. IMS/Universidade do Estado do Rio de Janeiro, 2008.

Assunção, Vânia Noeli Ferreira de. O satânico doutor GO: A ideologia bonapartista de Golbery do Couto e Silva. Dissertação de mestrado. Pontifícia Universidade Católica de São Paulo, 1999.

Ávila S. J., Fernando Bastos. A cartilha do aprendiz de sociólogo. Diário de Notícias, 19/12/1954.

Azevedo, Ariston. A sociologia antropocêntrica de Alberto Guerreiro Ramos. Tese de doutorado. Universidade Federal de Santa Catarina, 2006.

Barbosa, Muryatan Santana. Guerreiro Ramos e o personalismo negro. Dissertação de mestrado. FFLCH/Universidade de São Paulo, 2004.

Bariani Junior, Edson. Guerreiro Ramos e a redução sociológica: capitalismo e sociologia no Brasil. Tese de doutorado. Universidade Estadual de São Paulo, 2008.

A sociologia no Brasil: uma batalha, duas trajetórias (Florestan Fernandes e Guerreiro Ramos). Dissertação de mestrado. Universidade Estadual de São Paulo, 2003.

Biegel, Fernanda. Autonomia y dependencia académica. Universidad e investigación científica en un circuito periférico. Buenos Aires: Biblos, 2010.

Bourdieu, Pierre. As regras da arte: gênese e estrutura do campo literário. São Paulo: Companhia das Letras, 1996.

Alta costura e alta cultura. In: Questões de sociologia. Rio de Janeiro: Marco Zero, 1983.

Brasil Junior, Antonio. Passagens para a teoria sociológica: Florestan Fernandes e Gino Germani. Tese de doutorado. PPGSA/Universidade Federal do Rio de Janeiro, 2011.

Camic, Charles. Reputation and predecessor selection: Parsons and the institutionalists. American Sociological Review, 1992, 57/4, p. 421-445. 
Chauí, Marilena \& Franco, Maria Sylvia de Carvalho. Ideologia e mobilização popular. Rio de Janeiro: Paz e Terra, 1978. Connell, Raewyn. Southern theory: the global dynamic of knowledge in social science. Cambridge: Polity Press, 2007.

Côrtes, Norma. Esperanças e democracia: as ideias de Álvaro Vieira Pinto. Belo Horizonte: Ed. UFMG, 2003.

Cruz, José Saraiva. Guerreiro Ramos e a construção ideológica do nacionalismo desenvolvimentista. Dissertação de mestrado. Universidade do Estado do Rio de Janeiro, 2002.

Ferreira, Jorge. O populismo e sua história: debate e crítica. Rio de Janeiro: Civilização Brasileira, 2001.

Garcia, Ramon Moreira. A via de um Guerreiro... com sabedoria e senso de humor: uma sinopse da obra de Guerreiro Ramos. Revista de Administração Pública, 1983, 17/1, p. 107-126.

Gorender, Jacob. Correntes sociológicas no Brasil. In: Ramos, Alberto Guerreiro. A redução sociológica. Rio de Janeiro: Ed. UFRJ, 1996.

Guimarães, César. "Prefácio”. In: Côrtes, Norma. Esperanças e democracia: as ideias de Álvaro Vieira Pinto. Belo Horizonte: Ed. UFMG, 2003.

Jauss, Hans. Toward an œsthetic of reception. Minneapolis: University of Minnesota Press, 1982.

Literary history as a challenge to literary theory. New Literary History, 1970, 2/1, p. 7-37.

Joas, Hans \& Knobl, Wolfgang. Social theory. Twenty introductory lectures. Cambridge: Cambridge University Press, 2009.

Hecksher, Mario Henrique. Guerreiro Ramos - sociólogo da sociologia nacional (um diálogo com Florestan Fernandes). Tese de doutorado. Universidade Federal do Rio de Janeiro, 2004. Lahuerta, Milton. Intelectuais e transição: entre a política e a profissão. Tese de doutorado. FFLCH/Universidade de São Paulo, 1999.

Lamont, Michele. How to become a dominant French philosopher: The case of Jacques Derrida. The American Journal of Sociology, 1987, 93/3, p. 584-622.

Leite, Dante Moreira. O caráter nacional brasileiro: História de uma ideologia. São Paulo: Ática, 1992. 
Maio, Marco Chor. Uma polêmica esquecida: Costa Pinto, Guerreiro Ramos e o tema das relações raciais. Disponível em<http://www.scielo.br/scielo.php?pid=S0011-5258199 7000100006\&script=sci_arttext>. Acesso em 9 jan. 2012.

Martins, Tatiana Gomes. Florestan Fernandes e Guerreiro Ramos: para além de um debate. Tese de doutorado. PPGS/Universidade Estadual de Campinas, 2008.

Matta, João Eurico. Alberto Guerreiro Ramos. Reflexão preliminar sobre sua trajetória intelectual, em homenagem póstuma. Revista de Administração Pública, 1983, 17/1, p. 85106.

McLaughlin, Neil. How to become a forgotten intellectual: intellectual movements and the rise and fall of Erich Fromm. Sociological Forum, 1998, 13/2, p. 215-246.

Miceli, Sérgio (org.). História das ciências sociais no Brasil. São Paulo: Vértice, 1989.

Condicionantes do desenvolvimento das ciências sociais. In: (org.). História das ciências sociais no Brasil. São Paulo: Vértice, 1989.

Mota, Carlos Guilherme. Ideologia da cultura brasileira (19331974). São Paulo: Ática, 1977.

Motta, Luiz Eduardo. O ISEB no banco dos réus. Comum, 2000, 5/15, p. 119-145.

Nunes, Benedito. Considerações sobre a redução sociológica. In: Ramos, Alberto Guerreiro. A redução sociológica. Rio de Janeiro: Ed. UFRJ, 1996.

Oliveira, Lúcia Lippi. A sociologia do Guerreiro. Rio de Janeiro: Ed. UFRJ, 1995.

Oliveira Filho, Virgílio Roma de. Dualidade e revolução no pensamento isebiano: as visões de Hélio Jaguaribe e Nelson Werneck Sodré. Tese de doutorado. CPDA/Universidade Federal Rural do Rio de Janeiro, 1999.

Ortiz, Renato. Cultura brasileira e identidade nacional. São Paulo: Brasiliense, 1985.

Paiva, Vanilda. Paulo Freire e o nacionalismo-desenvolvimentista. Rio de Janeiro: Civilização Brasileira, 1980.

Pinheiro, Cláudio. Direct and indirect transitivity. The receptions of Dependency Theory in India and Singapore and other dialogues between intellectual peripheries from the 
Global South. Trabalho apresentado no World Social Sciences and Humanities Network Meeting. Buenos Aires, Argentina, 2010.

Pécaut, Daniel. Os intelectuais e a política no Brasil: entre o povo e a nação. São Paulo: Ática, 1990.

Rago, Elizabeth Juliska. O nacionalismo no pensamento de G. Ramos. Dissertação de mestrado. Pontifícia Universidade Católica de São Paulo, 1993.

Ramos, Alberto Guerreiro. A redução sociológica. Rio de Janeiro: Ed. UFRJ, 1996.

. Introdução crítica à sociologia brasileira. Rio de Janeiro: Ed. UFRJ, 1995.

A nova ciência das organizações. Uma reconceituação da Riqueza das Nações. Rio de Janeiro: Ed. FGV, [1981] 1989.

A nova ignorância e o futuro da administração pública na América Latina. Revista de Administração Pública, 1983, 17/1, p. 32-65.

A teoria administrativa e a utilização inadequada de conceitos. Revista de Administração Pública, 1983, 17/1, p. 66-76. . Administração e estratégia do desenvolvimento: elementos de uma sociologia especial da administração. Rio de Janeiro: Ed. FGV, 1966.

.W. I. Thomas (1863-1947). Revista do Serviço Público, 1948a, 2/1-2, p. 159-160.

Pequena bibliografia para o estudo da assimilação e aculturação. Revista do Serviço Público, 1948b, 2/3-4, p. 179182.

Administração e política à luz da sociologia. Revista do Serviço Público, 1946a, IX, 3/1, p. 5-11.

A sociologia de Max Weber (sua importância para a teoria e a prática da administração). Revista do Serviço Público, 1946b, 3/2-3, p. 129-139.

Rufino, Joel. O negro como lugar. In: Ramos, Alberto Guerreiro. Introdução crítica à sociologia brasileira. Rio de Janeiro: Ed. UFRJ, 1995, p. 19-29.

Schwartzman, Simon. Contribuição de Guerreiro Ramos para a sociologia brasileira. Revista de Administração Pública, $1983,17 / 2$, p. $30-34$. 
Shiota, Ricardo Ramos. Os pressupostos do debate intelectual entre Florestan Fernandes e Guerreiro Ramos nas décadas de 1950 e 1960: duas versões de teoria crítica da sociedade brasileira? Dissertação de mestrado. Universidade Estadual de São Paulo, 2010.

Souza, Márcio Ferreira de. A construção da concepção de desenvolvimento nacional no pensamento de Guerreiro Ramos. Dissertação de mestrado. FAFICH/Universidade Federal de Minas Gerais, 2000.

Toledo, Caio Navarro. ISEB: ideologia e política na conjuntura do golpe de 1964. In: . Intelectuais e política no Brasil: a experiência do ISEB. Rio de Janeiro: Revan, 2004, p. 137-164. . ISEB: fábrica de ideologias. São Paulo: Ática, 1977. 
Palavras-chave

Alberto Guerreiro Ramos;

História da sociologia;

Sociologia das reputações;

Teoria da recepção.

Keywords

Alberto Guerreiro Ramos;

History of sociology; Sociology of reputations;

Reception theory.

\section{Resumo:}

O artigo analisa as diferentes fases na recepção da obra do sociólogo Alberto Guerreiro Ramos com o objetivo de entender as mudanças na sua reputação intelectual. A hipótese principal do texto diz respeito à necessidade de relacionar o discurso sociológico de Guerreiro Ramos ao ambiente global da sociologia entre os anos de 1950 e 1980. Para tanto, o autor relê a produção intelectual de Guerreiro Ramos para evidenciar seus interlocutores intelectuais e suas fontes teóricas. Esse método me permite comprovar a atualização do autor em relação às principais tendências sociológicas do período, desfazendo sua clássica representação como um intelectual outsider.

\section{Abstract:}

The article analyzes the different receptions of the work of Brazilian sociologist Alberto Guerreiro Ramos to understand how his intellectual reputation changed. The main hypothesis is that one needs to articulate Ramos' sociological discourse to global sociology between 1950 and 1980. In order to achieve this goal, the author analyzes Ramos' intellectual production to illustrate both his sources and intellectual peers. This method proves how Ramos was up to date with the main sociological trends of his time. Therefore, his classical description as an outsider must be avoided. 